\title{
COCHRANE CORNER
}

\section{Prevention of injuries at home}

$\mathrm{T}$ he home is one of the most common settings in which injuries are sustained, with young children and the elderly being at most risk. In the UK, the number of deaths resulting from injuries in the home exceeds the number resulting from road-traffic crashes. ${ }^{1}$ In Australia, it is estimated that for the year $2002,41.5 \%$ of all fatal injuries occurred at home. ${ }^{2}$ It is therefore unsurprising that the home environment receives attention as a setting for interventions in prevention of injuries, and subsequently there have been a number of Cochrane Systematic Reviews published on the topic, summarized below.

\section{MODIFICATION OF THE HOME ENVIRONMENT FOR THE REDUCTION OF INJURIES}

This review by Lyons et $a^{3}$ examined all randomized controlled trials (RCTs) of interventions which focus on reducing physical hazards within the home. The authors identified 19 eligible trials, two of which investigated a home environment modification as the sole intervention with the remaining 17 using a combined approach with other strategies. Overall, the authors found the trials to be of insufficient size and quality to obtain confident findings, concluding that "there is little high-level scientific evidence for the modification of the built home environment as a method of reducing injury risk". The review authors highlight the current poor evidence-base on which to devise policy and determine relative cost-effectiveness, and call for the conduct of better quality and adequately powered studies of such interventions.

\section{HOME SAFETY EDUCATION AND PROVISION OF SAFETY EQUIPMENT FOR PREVENTION OF INJURIES}

This review by Kendrick et $a l^{4}$ is a large review containing 80 controlled intervention studies. All the studies examined a home safety education intervention (with or without the provision of safety equipment) on the occurrence of child injury, safety practices or possession of safety equipment. Twenty-three of the included studies were RCTs. The review team found evidence that home safety education is effective in increasing a range of safety practices, such as safe storage of medicines, safe hot water temperatures and fitted stair gates. However, there is a lack of evidence to indicate whether such interventions are effective in actually reducing the number of injuries. The authors suggest that there is a need for further large or multiple smaller trials, which are sufficiently homogeneous to enable pooling of data.

\section{INTERVENTIONS FOR PROMOTING SMOKE ALARM OWNERSHIP AND FUNCTION}

This review by DiGuiseppi et al examined controlled studies that evaluated the effect of any intervention designed to increase the prevalence of owned or properly functioning smoke alarms on the risk of fire-related injuries, fires, and smoke alarm ownership or function. Thirteen RCTs and eight non-randomized studies were identified. The results indicate that counselling and educational interventions have a modest effect on the likelihood of owning an alarm and having a functional alarm; however, the results were sensitive to the quality of the trial. There were no data from RCTs on fire-related injuries, although evidence from non-randomized studies suggested that community smokealarm give-away programmes reduce fire-related injuries. The authors call for further trials that investigate fire-related injuries as an outcome, and use adequate allocation concealment and blinded-outcome assessment. An update of this review is in progress.

\section{POOL FENCING FOR PREVENTING DROWNING IN CHILDREN}

This review by Thompson et $a l^{6}$ examined all controlled studies examining pool fencing with a comparison group, on the risk of drowning in children under 14 years of age. The authors found no eligible trials but three case-control studies meeting the inclusion criteria. The results of these studies indicate that pool fencing significantly lowers the risk of drowning, preventing approximately three-quarters of all child drownings in pools. Isolation fencing (enclosing the pool only) was found to be more effective than perimeter fencing (enclosing property and pool). The authors conclude that legislation should require isolation fencing with secure self-latching gates for all pools, both public and privately owned. Additional studies would also be useful to obtain a more precise estimate of the protective effect of fencing.

These four systematic reviews indicate that there are some promising interventions for prevention of injury in the home. However, it was difficult for any of the reviews to draw confident conclusions regarding the effectiveness of the interventions in reducing injuries. Each review calls for the conduct of further, methodologically stronger studies to enable more confident statements of effectiveness and to provide greater precision of effect estimates. In particular, there is a need for further studies with adequate allocation concealment and blinding, and those that measure injury occurrence as an outcome instead of relying on behavioural data, which are difficult to translate into actual injury risk. Finally, it would be preferable for future studies to be designed with the aim of contributing to the wider evidence-base, and not solely as stand-alone evaluations.

The full text of these reviews and systematic reviews on other injury prevention topics are available on the Cochrane Database of Systematic Reviews (http://www.thecochranelibrary.com).

For further information about the Cochrane Injuries Group, visit http:// www.cochrane-injuries.lshtm.ac.uk.

Katharine Kerr

Review Group Co-ordinator Coahrane Injuries Group, Nutrition \& Public Health Intervention Research Unit, London School of Hygiene \& Tropical Medicine, Room 280, North

Countryard, Keppel Street, London WCIE THT UK; Katharine.Ker@lshtm.ac.uk

\section{REFERENCES}

1 British Medical Association. Housing and health: building for the future, UK, BMA, 2003

2 Kreisfeld R, Newson R, Harrison J. 2004. Injury deaths, Australia 2002. Injury Research and Statistics Series Number 23. Adelaide: AlHW (AlHW cat no, INJCAT 65), 2004.

3 Lyons RA, John A, Brophy S, et al. Modification of the home environment for the reduction of injuries. Cochrane Database Syst Rev 2006;(4):CD001877.

4 Kendrick D, Coupland C, Mulvaney C, et al. Home safety education and provision of safety equipment for injury prevention. Cochrane Database Syst Rev 2007:1:CD005014.

5 DiGuiseppi C, Higgins JPT. Interventions for promoting smoke alarm ownership and function. Cochrane Database Syst Rev 2001 ;2:CD002246.

6 Thompson DC, Rivara FP. Pool fencing for preventing drowning in children. Cochrane Database Syst Rev 1998; 1:CD001047. 


\section{PostScript}

\section{CALENDAR}

1st Injury Prevention Conference for the UK and Ireland: Research into Practice for Child and Adolescent Injury

13-14 September 2007, Bristol, UK. The conference will focus on the prevention of unintentional injury to children and adolescents. Emphasis will be placed on an evidence-based approach and how to translate evidence into practice. Further information: http://tinyurl. com/2536lf

\section{World Water Safety 2007}

27-29 September 2007, Porto, Portugal. The conference is designed for those with an interest in exchanging information globally on the latest developments in prevention, rescue, and treatment of drowning and other aquatic injuries. The hosts are the Instituto de Socorros a Náufragos (ISN) and the Associação de Nadadores Salvadores (ASNASA). Further information: http://tinyurl.com/y7esew

Injury Prevention Network Aotearoa of New Zealand (IPNANZ) 2007 Conference

29-31 October 2007, Napier, New Zealand. The closing date for the submission of abstracts is
15 June 2007. Further information: http:// tinyurl.com/yrq8nv

\section{4th Asian Regional Conference on Safe Communities}

21-24 November 2007, Bangkok, Thailand. The theme of the meeting is Incorporating global thinking; cultivating local strategy. The conference will be followed by a visit to a site of the 2005 tsunami. Further information: http:/ safethai2007.com

\section{World Congress on Neck Pain}

20-22 January 2008, Los Angeles, USA. The congress will present the latest scientific research on the prevention, diagnosis, and management of neck pain. The congress themes are public health, healthcare and automobile safety. The closing date for the submission of abstracts is 13 August 2007. Further information: http://neckpaincongress org

\section{9th World Conference on Injury Prevention and Safety Promotion}

15-17 March 2008, Merida, Mexico. The conference will give special attention to the processes of globalization and their implications for injuries and violence. The World Health Organization is urging governments to address the two main themes of violence and traffic accidents. The conference will also emphasize the global patterns in technological and epidemiological transitions, proposing international collaboration as a fundamental strategy for the design and promotion of policies for injury prevention and safety promotion. Early registration and the call for abstracts are already open. Further information: http:/www.safety2008mx.info/ing/

\section{CORRECTIONS}

doi: 10.1136/ip.2007.015412.corr 1

An error occurred in the paper by Ker and Ivers in the April 2007 issue of the journal (Inj Prev 2007;13:141). The paper was authored by $\mathrm{K}$ Ker and $\mathrm{R}$ Ivers, not by $\mathrm{K}$ Kerr, as was printed in the journal.

doi: 10.1136/ip.8.297.corr 1

Several errors occurred in the article by Borrel C, Rodriguez M, Ferrando J, et al. Role of individual and contextual effects in injury mortality: new evidence from small area analysis. Inj Prev 2002;8:297-302. The corrected text and figure 1 are available on our website (http://injuryprevention.bmj.com/supplemental). 